\title{
A clinical audit of hysteroscopy in a tertiary care teaching. What challenges did we face?
}

\author{
Anjali Mundkur, Prashanth K. Adiga*, Pratap Kumar
}

Department of Reproductive Medicine and Surgery, Kasturba Medical College, MAHE university, Manipal, Karnataka, India

Received: 02 June 2021

Revised: 06 June 2021

Accepted: 18 June 2021

\section{*Correspondence:}

Dr. Prashanth K. Adiga,

E-mail: prashanth.adiga@manipal.edu

Copyright: (C) the author(s), publisher and licensee Medip Academy. This is an open-access article distributed under the terms of the Creative Commons Attribution Non-Commercial License, which permits unrestricted non-commercial use, distribution, and reproduction in any medium, provided the original work is properly cited.

\section{ABSTRACT}

Background: The aim of the study was to evaluate indications, operative findings and complications in patients undergoing hysteroscopy.

Methods: The data of all patients who underwent hysteroscopy in the department of obstetrics and gynecology in a tertiary care teaching hospital were included retrospectively from November 2017 to October 2018.

Results: There were 59 patients who had hysteroscopy for various indications. Twelve patients and forty-seven patients were subjected to diagnostic and operative hysteroscopy respectively. Indications for diagnostic hysteroscopy were for postmenopausal bleed (3), carcinoma of the breast on tamoxifen with bleeding PV (3), recurrent implantation failure (6). Operative hysteroscopy was performed for endometrial polyp (30), myomectomy (9), septal resection (7), copper T removal (1). Complications of hysteroscopy were: media efflux and poor visualization in $10(17 \%)$, minor hemorrhage (9) $15.1 \%$, perforation $2(3.3 \%)$. Minor hemorrhage was managed with tranexamic acid. The perforation in two patients happened during the dilatation of the cervix with metal dilators.

Conclusions: One of the major challenges encountered was the efflux of the distension media due to excessive cervical dilatation, which did not provide satisfactory hysteroscopic view. Another complication was perforation during cervical dilatation using Hegars dilator. Use of misoprostol and the use of small sheath hysteroscopes have minimized the need for cervical dilatation.

Keywords: Hysteroscopy, Complications, Perforation

\section{INTRODUCTION}

Hysteroscopy is a procedure which is minimally invasive and is used in the diagnosis and management of cervical canal and uterine cavity disorders. ${ }^{1}$ The two types of hysteroscopic procedures include diagnostic and operative hysteroscopy. ${ }^{1}$

Hysteroscopy has replaced and overcome the short coming of dilatation and curettage. With the advancement of technology and miniaturization of tools, the concept of 'see and treat' hysteroscopy is becoming popular. ${ }^{2,3}$ The endometrial cavity needs to be distended for optimal visualization to diagnose and perform surgical procedures. ${ }^{5}$ The media commonly used are $\mathrm{CO}_{2}$ gas, highviscosity $32 \%$ dextran 70 , and several low-viscosity fluids, including non-electrolytic solutions like glycine, sorbitol, mannitol, and dextrose in water, and electrolyte-containing isotonic solutions such as normal saline. ${ }^{5}$ This study focused to find out the indications, nuances and complications with hysteroscopy.
Aim
The aim of the study was to evaluate the indications and complications of women undergoing hysteroscopy. 


\section{METHODS}

This was a retrospective study done in the department of obstetrics and Gynaecology in a tertiary care teaching hospital in Kasturba Medical College, Manipal from November 2017 to October 2018. All the patients who underwent hysteroscopy (diagnostic as well as operative) were taken for the study. This was an audit of hysteroscopy, so there were no inclusion or exclusion criteria. The patient's history, physical and gynecological examination, followed by a transvaginal ultrasound was done. Patients were then subjected to diagnostic hysteroscopy on OPD basis. If patient experienced discomfort or satisfactory views were not obtained, patients were subjected to diagnostic hysteroscopy under anesthesia. All operative hysteroscopies were performed under general anesthesia. Operative findings were noted. In cases of operative hysteroscopy for polyps and sub mucous fibroid polyp excision, the products were sent for histopathological examination. The data of the patients were recorded in excel sheet.

\section{RESULTS}

There were total of 59 patients who were subjected to hysteroscopy. There were twelve patients who underwent diagnostic hysteroscopy and forty-seven of them had operative hysteroscopy. Age of patients ranged from 2267 years. The indications for diagnostic and operative hysteroscopy are mentioned in Table 1. Indications for diagnostic hysteroscopy were as follows. Evaluation of post-menopausal bleeding $3(25 \%)$, carcinoma of breast on tamoxifen therapy with bleeding per vagina 3 (25\%) and recurrent implantation failure $6(50 \%)$. Indications for operative hysteroscopy were for endometrial polyps 30 $(63.8 \%)$, sub mucous fibroid $9(19.1 \%)$ and septal resection $7(14.8 \%)$ and retrieval of embedded $\mathrm{Cu}-\mathrm{T} 1$ $(2.1 \%)$.

Table 1: Depicting the indications for diagnostic and operative hysteroscopy.

\begin{tabular}{|c|}
\hline $\begin{array}{l}\text { Indications of diagnostic } \\
\text { hysteroscopy }(\mathrm{N}=12)\end{array}$ \\
\hline Post-menopausal bleeding \\
\hline $\begin{array}{l}\text { Carcinoma of breast on tamoxifen } \\
\text { therapy with bleeding per vagina }\end{array}$ \\
\hline Recurrent implantation failure \\
\hline
\end{tabular}

Most of the patients who were subjected to operative hysteroscopy were from infertility division of the department. In the thirty patients who were diagnosed and treated for endometrial polyps by hysteroscopy, transvaginal ultrasound could detect only twenty-two cases $(74.4 \%)$ of polyps and eight cases (26.6\%) were missed. All the thirty patients had an endometrial thickness of $>13 \mathrm{~mm}$. Among the nine patients who were diagnosed and treated for sub mucous fibroid, a diagnosis of fibroid was made in eleven cases. Transvaginal ultrasound over diagnosed sub mucous fibroid polyp in 2 patients.

The complications encountered in our series are listed in Table 2. The common complications noted were poor visualization due to media efflux $10(17 \%)$, minor hemorrhage $9(15.2 \%)$ and perforation $2(3.3 \%)$.

Table 2: Depicting the complications encountered.

\begin{tabular}{|ll|}
\hline $\begin{array}{l}\text { Complications noted } \\
\text { Media efflux and poor } \\
\text { visualization }\end{array}$ & Number (\%) \\
\hline Minor hemorrhage & $10(17)$ \\
\hline Perforation & $09(15.2)$ \\
\hline
\end{tabular}

\section{DISCUSSION}

In this audit, the numbers of patients are very small to make any conclusions. This study does throw light on indications and the complications. The common indication

\begin{tabular}{ll}
$\begin{array}{l}\text { Indications of operative } \\
\text { hysteroscopy }(\mathbf{N}=47)\end{array}$ & Number $(\%)$ \\
\hline $\begin{array}{l}\text { Endometrial polyps } \\
\text { Submucous fibroid, underwent } \\
\text { myomectomy }\end{array}$ & $30(63.8)$ \\
\hline Septal resection & $9(19.1)$ \\
Copper- T removal & $7(14.8)$ \\
\hline
\end{tabular}

for diagnostic hysteroscopy in our audit was recurrent implantation failure. In the study by Beukenholdt et al, the commonest indication was menorrhagia and intermenstrual bleeding. ${ }^{6}$ Uterine perforation was encountered in $3.3 \%$ of patients in our series. The perforation occurred during dilatation of the cervix with Hegar's dilator. The incidence of uterine perforation is $0.12-3 \% .^{7-9}$ Perforation may occur during dilatation of the cervix or as a result of hysteroscopic procedure ${ }^{5}$. When perforation occurs during cervical dilatation, there are no other associated injuries. Utilizing uterine probe, transabdominal or transvaginal ultrasound will help to delineate the cervical canal and its relationship with uterine axis. ${ }^{1}$ Use of misoprostol may reduce the difficulty of hysteroscope into the uterine cavity. ${ }^{10}$ The use of small diameter flexible or rigid hysteroscope helps in visual control as the cervix is dilated with the tip of hysteroscope. ${ }^{11}$ Transabdominal ultrasound offers the advantage of viewing the uterine cavity, which is filled by the distension media.

Minor hemorrhage was observed in $15.2 \%$ of patients in our series. This was managed by administering injection Tranexamic acid $500 \mathrm{mg}$ intravenously. Hemorrhage is defined as any procedure which required blood transfusion or any hemostatic intervention. ${ }^{9}$ This complication has an incidence of $0.61 \%$, in a study by Agostini et al. ${ }^{12}$ Risk of hemorrhage depended on the type of operative intervention. It was five times higher in adhesiolysis, when compared with other operative hysteroscopic procedures. ${ }^{12}$ 
Managing postoperative bleeding include use of antifibrinolytic agents, balloon tamponade using Foley catheter, uterine artery embolization or hysterectomy in rare cases. ${ }^{1,13}$ One of the distressing problems encountered in our series was poor visualization due to media efflux. This was due to dilatation of the cervix, which let to efflux of the media. Misoprostol administration before hysteroscopy reduces the cervical resistance and hence the need for cervical dilatation. As stated earlier, the need for cervical dilatation is greatly reduced by the use of small diameter flexible or rigid hysteroscope. Another method of minimizing the media efflux is hold the anterior and posterior lips of the cervix using an Allis forceps and approximating the lips of the cervix. This helps in optimizing the visual field (personal communication: Dr. Vinayak Mahajan).

\section{Limitations}

The number of patients who underwent hysteroscopy were small, to make a definite conclusion. Secondly, hysteroscopy was performed by medical personnel of varying experience (senior resident to associate professor), which may not truly reflect the complication rates.

\section{CONCLUSION}

This audit helped us to identify the problems faced and how they were tackled. There is a learning curve to acquire hysteroscopy skills. The complications rate in this audit was similar to the those of other studies. Periodic audits help us to know if there have been improvements in the learning curve and minimizing the expected complications.

\section{ACKNOWLEDGMENTS}

We acknowledge the help rendered by the following staff of the department of obstetrics and gynaecology, KMC Manipal, Dr. Murlidhar V. Pai, Dr. Jyothi Shetty, Dr. Shyamala G., Dr. Shreepad Hebbar, Dr. Akhila Vasudeva and Dr. Jayaram Nambiar.

\section{Funding: No funding sources}

Conflict of interest: None declared

Ethical approval: The study was approved by the Institutional Ethics Committee

\section{REFERENCES}

1. Zimmer M, Pomorski M, Kaminski P, Doniec J, Huras $\mathrm{H}$, Sieroszewski P, et al. Polish Society of
Gynecologists and Obstetricians Guidelines for the application of hysteroscopy in gynecology. Ginekol Pol. 2019;90(8):482-9.

2. Wortman M. "See-and-Treat" Hysteroscopy in the Management of Endometrial Polyps. Surg Technol Int. 2016;28:177-84.

3. Gambadauro P, Martínez MMA, Torrejon R. When is see-and-treat hysteroscopic polypectomy successful? Eur J Obstet Gynecol Reprod Biol. 2014;178:70-3.

4. The Use of Hysteroscopy for the Diagnosis and Treatment of Intrauterine Pathology: ACOG Committee Opinion, Number 800. Obstet Gynecol. 2020;135(3):138-48.

5. Munro MG. Complications of hysteroscopic and uterine resectoscopic surgery. Obstet Gynecol Clin North Am. 2010;37(3):399-425.

6. Beukenholdt R, Guerrero K. An audit of a specialist registrar-run outpatient diagnostic hysteroscopy service in a district general hospital. J Obstet Gynaecol. 2003;23(3):294-6.

7. Aydeniz B, Gruber IV, Schauf B, Kurek R, Meyer A, Wallwiener D. A multicenter survey of complications associated with 21,676 operative hysteroscopies. Eur J Obstet Gynecol Reprod Biol. 2002;104(2):160-4.

8. Jansen FW, Vredevoogd CB, Ulzen K, Hermans J, Trimbos JB, Trimbos KTC. Complications of hysteroscopy: a prospective, multicenter study. Obstet Gynecol. 2000;96(2):266-70.

9. Propst AM, Liberman RF, Harlow BL, Ginsburg ES. Complications of hysteroscopic surgery: predicting patients at risk. Obstet Gynecol. 2000;96(4):517-20.

10. Hwang JY, Song SH. Optimal Dose of Vaginal Misoprostol for Cervical Ripening before Hysteroscopy: A Randomized Double-Blind Study. J Minim Invasive Gynecol. 2018;25(6):1031-4.

11. Bettocchi S, Bramante S, Bifulco G, Spinelli M, Ceci $\mathrm{O}$, Fascilla FD, et al. Challenging the cervix: strategies to overcome the anatomic impediments to hysteroscopy: analysis of 31,052 office hysteroscopies. Fertil Steril. 2016;105(5):16-e17.

12. Agostini A, Cravello L, Desbriere R, Maisonneuve AS, Roger V, Blanc B. Hemorrhage risk during operative hysteroscopy. Acta Obstet Gynecol Scand. 2002;81(9):878-81.

13. Eng MK, Langebrekke A, Hudelist G. Complications in operative hysteroscopy - is prevention possible? Acta Obstet Gynecol Scand. 2017;96(12):1399-1403.

Cite this article as: Mundkur A, Adiga PK, Kumar P. A clinical audit of hysteroscopy in a tertiary care teaching. What challenges did we face? Int J Reprod Contracept Obstet Gynecol 2021;10:2620-2. 